\title{
RESEARCH TRENDS IN JAPANESE ON CHINESE AGRICULTURE MANAGEMENT (FOCUSING ON PERIOD AFTER RURAL REFORM IN 1978)
}

\author{
Bai Suxiang \\ Graduate School of Agriculture, Kyoto University, Japan. \\ E-mail: hakumotoka@gmail.com \\ Citation: Suxiang, B. 2019. Research Trends In Japanese on Chinese Agriculture Management \\ (Focusing on Period After Rural Reform in 1978), Japan. J. Asian Rur. Stud. 3(2): 171-185
}

\begin{abstract}
The purpose of this research is to examine the characteristics of the Japanese research trend on Chinese family farm management published after the Chinese rural reform in 1978. The whole 152 articles were collected under the keyword of Chinese Agriculture Management through CiNii that is the most reliable academic information database in Japan. Based on article productivity the study extracted the four stage of research development: incubating stage, growing stage, peak stage, and stabilizing mature stage. Research subject categorization unveiled two general research frameworks: macro approach framework and micro approach framework. In the macro framework, farm management is structurally grasped under the relationship with external or environmental conditions surrounding farm management entities. In the micro framework farm management is grasped within internal structural relationship of family based on inputs (land and labor) and output (income). For solving the weakness of Chinese family farm holding a small land, the study extracted two strategic frameworks of integration in farm management: agricultural industrialization and farm cooperative movement. The former is a vertical integration and the latter is a horizontal integration of farm management. Those integrations of farm management require not only macro and micro level research but also mezzo(middle) approach which focuses on the relationships between community or village and farm family. Especially this mezzo approach is important to understand the reality of farm management under the on-going situation in which many farm families depend on both agriculture and non-agriculture jobs. The fact that the dates for publications in China are limited at the macro-level of nation, province and city has created the research tendency towards bipolar differentiation in macro and micro level research. Thus mezzo-level research on towns and villages has become more important.
\end{abstract}

Keywords: Chinese Agriculture Management; Japanese research; Mezzo (middle) approach; Research development stage

\section{Introduction}

Since 2000, China's agriculture sector has undergone drastic changes that can be considered rare compared with developments in the rest of the world. This rapid change can be traced to the rural reform that began in 1978 and introduced the agricultural production contracting system. In 1983, people's communes were dismantled, leading to the spread of the public of family. As a result, small-scale family agricultural management became the entity. According to the Chinese statistics yearbook of 2014, the national average family-run land size is only $1.52 \mathrm{mu} /$ person $(1 \mathrm{mu} \approx 6.67 \mathrm{area})$. In 
small-scale land management, livelihood improvement is difficult through agricultural income only. Thus, income economic elements.

According to the economic development mechanism, urbanization evolves with economic development based on industrial development. Many rural labor populations move to cities. China is no exception to trend. Rural and urban populations are regulated by family register in rural area and cities, respectively (Shiraishi,1997). According to the Chinese Statistics Yearbook, the percentage of rural population in the total national population was $78.9 \%$ in 1982 . In 2013 , the rural population decreased to $46.3 \%$ of the total, whereas the urban population increased.

In the farming economy, the tendency of outside agricultural income is remarkably larger than that of agricultural income. The China Statistical Yearbook show that farm household income accounted for approximately 70\% of farmers' income in the $1990 \mathrm{~s}$, but this figure decreased to $40 \%$ in 2016 . No data are available on specialized farmers. However, in 2016, self-employed farmers accounted for $56 \%$ of the national average, whereas non-agricultural wage income farmers, who were estimated to be close to second class farmers, accounted for 30\% (Suganuma,2016).

Rapid changes in eating habits are occurring along with economic development. In response to this change in market needs, farmer's crops have undergone a major transformation from traditional (wheat, rice, corn) to economic (vegetables, fruits). In terms of cultivated area across China, although the aggregate grown area for agricultural products increased by $10 \%$ from 150,104 ha in 1978 to 164,627 ha in 2013 , the area covered by food in the same period decreased by $7 \%$ from 120,587 ha to 111,956 ha. Vegetable cultivation showed a significant increase by 6.3 times from 3,331 ha to $20,899 \mathrm{ha}$, and the fruit tree planting area exhibited the same trend. An increasing trend in economic crops, such as vegetables, is expected to earn higher income than food crops and reflects the result of farmer's crop selection.

The objective of the present study is to understand how research on agricultural management has changed in response to such environmental change surrounding rapid agricultural management in China. Although research on China's agricultural management have been conducted in many ways, focusing on research papers written in Japanese can show how these researchers have grasped Chinese agricultural management. Furthermore, this study focuses on research published from 1978, which marked the beginning of rural reforms, to subsequent years. We aimed to clarify the research trend by identifying the characteristics of each subject area and analysis method by extracting tasks that represent conceptual elements from themes discussed by each thesis. This approach enables us to examine the research achievements related to Chinese agricultural management, and the remaining issues viewed from Japanese literature.

\section{Method}

This study uses KJ method, which was developed by Jiro Kawakita, a Japanese cultural anthropologist. This method is a card organization technique that facilitates creative problem solving. The KJ method extracts important keywords from the collected non-numeric (verbal) information, organizes these keywords into conceptual groups based on similarity of meanings, and grasps the conceptual linkage structure. This method is characterized by the use of cards, each reflecting one keyword, and 
organizing the cards into groups of conceptual similarity to grasp the whole conceptual structure measured by quality.

As shown in Figure 1, the KJ method consists of the following five steps: (1) coverage or collection of verbal data, (2) label making or keyword extraction, (3) group organization or conceptual grouping of keywords, (4) illustration of linkage structure of conceptual groups, and (5) description of the quality of the entire information structure.

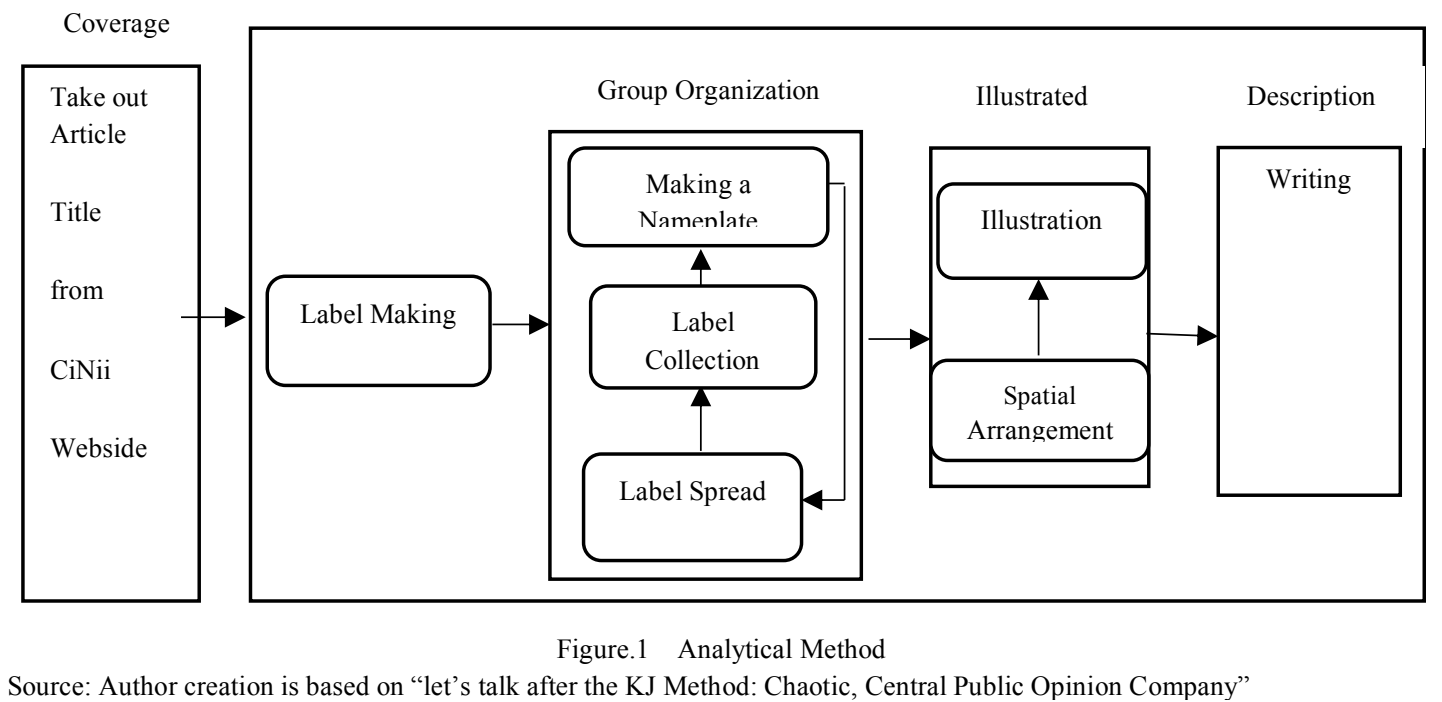

Each step is described in the following:

(1) Qualitative data collection. The data must be gathered in the reporting activity through field observation, discussion, and extraction from documents. In this study, the qualitative data of the titles in 152 journal articles were obtained from the CiNii website.

(2) Label making. Labeling or extracting keywords is an essential step because these keywords function as a base for further qualitative analysis. In this study, a total of 324 keywords were extracted from 152 articles. These 324 keywords were organized into 18 conceptual categories.

(3) Group organization. This step consists of the three sub-steps. (a) Label spread: Label sets can now be created as a result of label collection. Certain labels do not belong to any set. In other cases, the set contains two, three, four, and five labels. (b) Label collection: All the labels are read in a certain order, such as going down sequentially from the upper left side, then to the right in the same sequence. Finally, the labels are read all over again from the beginning. (c) Creating a nameplate: This task involves arrangement of the labeled data, in which the order is irrelevant.

(4) Illustrated. This step includes two sub-steps. (a) Spatial Arrangement. It means that if the content of the appeal of a bundle's nameplate takes a spatial 
arrangement, the most obvious composition on the meaning may be found immediately. However, sometimes after a lot of rearrangement, a composition that is convincing may be obtained. Also, cases exist where two or three convincing compositions may be obtained. When more than one convincing composition exist, the one that is most convincing should be adopted. (b) Illustration. The original label is attached to that position after the space arrangement is completed. Then, an "island" is created that encloses a set of original labels gathered in the first group organization as lines. The relationship among the "islands" is illustrated after this relationship has been analyzed. The illustration is written in "symbol mark". A title and a note are included at the end of the illustration.

(5) Description. The illustration is based on how to create a story. Two ways can be used to make a description: writing and oral presentation. The former is a more thorough method.

Many vague referents were found in this part. We revised it for clarity and sense. Check that the original meaning was retained.

However, sometimes after a lot of rearrangement, you may finally get a composition that is convincing. There are also cases where you can get two or three convincing compositions accordingly. In that case you can adopt which one I like the most. (4) illustration: when space arrangement is completed, first attach the original label to that position. Then, it is an island work that encloses a set of original labels gathered in the first group organization as lines like islands. I can illustrate after studying the relationship between the island and the island. In the illustration, write it in "symbol mark". It is worth noting that at the end of the illustration creation, you should include a title and note.

Figure 2. Group Organization Chart in this Paper

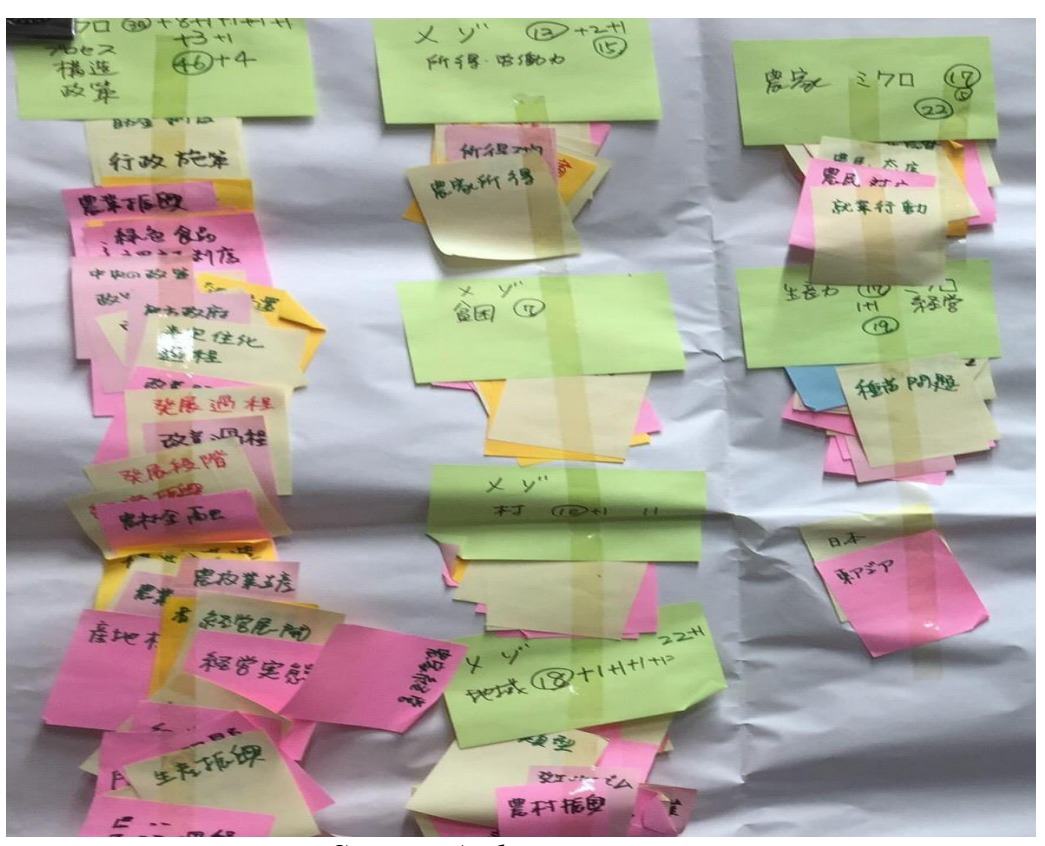

Source: Author creation 


\section{Results ad Discussion}

\subsection{Sources of Previous Research}

Although research on Chinese agricultural management has been published in various formats, in the current research, in principle, only Japanese papers published on the research site were delimited as analysis subjects. The site contains academic information such as papers, books, magazines, and doctoral dissertations. The site is the most popular database in Japan. We conducted a search on "China agricultural management" as keywords. A total of 152 Japanese papers after 1980 were recorded (Table 1). The literature collection period is limited to 1980 onwards because the early 1980 s were a period of structural change from the People's Commune of China Agriculture (1958-1970) to the family management stage (first half of 1980).

\subsection{Impact of Agri-Food System Led by MNCs}

Oligopolistic control by MNCs has encouraged trade in major commodities with MNCs leading the agri-food system. Table 3 is derived from Hisano (2011), which referred to Doris Fucks' estimate based on data from the German Bundestag. Evidently, there has been a movement toward oligopolization by big international companies trading in farm products. While the MNCs have a share of $70 \%$ of the total trade even in rice which people want to eat from their nation, the figure goes up to $90 \%$ for other products such as wheat, maize, and coffee.

Table 1. Selection of Papers

\begin{tabular}{c|c|c|c}
\hline Era & Keyword & Site & Papers \\
\hline 1980 & China Agriculture Management & CiNii & 152 \\
\hline
\end{tabular}

Source: Author creation

For such literature collection, a possibility exists that research that is unrelated to this study may be included, but such possibility was unavoidable due to limitations such as time and research funds. Despite these limitations, because CiNii is the most popular academic information database, the collection of research literature through the present invention enables us to identify the general characteristics of research on Chinese agricultural management written in Japanese.

\subsection{Basic Trends in Frequency of Presentation of Gathering Precedent Literature}

The results of classifying collected papers by age are shown in Table 2 . The period from 1980 to 2016 was basically measured at five-year intervals based on the number of articles published. Because few papers were published from 1980 to 1990, this period was summarized as one period. Furthermore, 2011 to 2016 was also summarized as one period. The 37-year period from 1980 to 2016 was divided into six periods and analyzed. 
Table 2. Classification of Collected Papers by Age

\begin{tabular}{l|c|c|c|c|c|c|c}
\hline \multicolumn{1}{c|}{ Steps } & $\begin{array}{c}1980- \\
1990\end{array}$ & $\begin{array}{c}1991- \\
1995\end{array}$ & $\begin{array}{c}1996- \\
2000\end{array}$ & $\begin{array}{c}2001- \\
2005\end{array}$ & $\begin{array}{c}2006- \\
2010\end{array}$ & $\begin{array}{c}2011- \\
2016\end{array}$ & $\begin{array}{c}1980- \\
2016\end{array}$ \\
\hline Papers (book) & 5 & 16 & 30 & 44 & 26 & 31 & 152 \\
\hline Ratio (\%) & 3.3 & 10.5 & 19.7 & 28.9 & 17.1 & 20.4 & 100 \\
\hline Papers (year) & 0.5 & 3.2 & 6 & 8.8 & 5.2 & 6.2 & 4.1 \\
\hline $\begin{array}{c}\text { Research development } \\
\text { stage }\end{array}$ & $\begin{array}{c}\text { Incubation } \\
\text { stage }\end{array}$ & \multicolumn{2}{|c|}{ Growth stage } & $\begin{array}{c}\text { Peak } \\
\text { stage }\end{array}$ & $\begin{array}{c}\text { Stable maturity } \\
\text { stage }\end{array}$ & \\
\hline
\end{tabular}

Source: CiNii website

\subsection{Impact of Agri-Food System Led by MNCs}

The results of classifying collected papers by age are shown in Table 2 . The period from 1980 to 2016 was basically measured at five-year intervals based on the number of articles published. Because few papers were published from 1980 to 1990, this period was summarized as one period. Furthermore, 2011 to 2016 was also summarized as one period. The 37-year period from 1980 to 2016 was divided into six periods and analyzed.

In Table 2, four indicators are shown, such as the total number of papers published in each period, the rate of collected articles in the 152 papers, and the annual average number of published papers (average number of published papers per year). The last indicator suggests the interest degree of research or the degree of concentration of the paper presentation. As 152 papers have been published over the entire 37-year period, the average number of published papers per year is 4.1 . Based on this average, when the number of annual published papers is larger than 4.1, the implication is that Japanese researchers are relatively interested in Chinese agricultural management.

From 1980 to 1990 , only five research papers were published, equivalent to $3.3 \%$ of the 152 collected papers. This result means that the number of annual published papers was only 0.5 , and the papers were published with a ratio of one in two years. In view of the subsequent research and development process, this period can be considered the infancy stage in the development of Japanese researchers on the Chinese family agricultural management. The important consideration is that in the early days since the introduction of the reform and open policy in 1978, a family contracting system was experimentally implemented in some rural areas. In 1982, "the family contract responsibility system" of agricultural land spread nationwide through the recruitment system. In 1984, the land contract period is generally set at more than 15 years in accordance with "Central Document No.1" (Li, 2011). A new agricultural management entity with the family as a unit was established at this time.

From 1991 to 1995 , only 16 papers were published, corresponding to $10.5 \%$ of 152 collected papers. The average annual number of papers published during this period was 3.2, dramatically increasing from the previous period. Combined with subsequent research trends, this period is the growth stage in the research development of Japanese scholars on Chinese agricultural management. At the same time, more Japanese researchers have become interested in Chinese agricultural management and the number of research papers in Japanese has increased since 1991. During this period, the growth of Chinese farming management research by the Japanese began. A "system of unified management combined with independent management" was introduced to supplement family management and regional-level village management. 
From 1996 to 2000,30 research papers equivalent to $19.7 \%$ of 152 collected papers were published. The average annual number of published papers increased to 6.0 , a situation that further promoted the growth trend of the previous period. During this period, "agricultural industrialization" was introduced to complement vertical integration of companies' and farmers' agricultural management to supplement family management. For example, in 1993, Shandong Province Zhucheng Prefecture launched agricultural industrialization that promoted agricultural enterprises integrally with farming enterprises. At the Third General Meeting of the $15^{\text {th }}$ Central Committee in 1998, "Resolution on some serious problems concerning central agriculture and rural construction" was made; this resolution was one of the ways in which agricultural industrialization management achieved the modernization of Chinese agriculture (Takahashi, 2008). In 1996, Leicester and Brown's "Who will Cultivate China: The Era of the Impending Food Crisis" was published in the United States. This article showed that interest in China's food supply problem was important as the background of research development.

The period from 2001 to 2005 saw the growth peak of research in the past decade. A total of 44 papers $(28.9 \%$ of the 152 gathered articles) were published, and the average annual number of papers published was 8.8, showing a high degree of concentration. With this background, China joined the World Trade Organization (WTO) in 2001, and the supply and demand of agricultural products from China greatly influenced the global agricultural market. Furthermore, in 2004, the Chinese government started a direct payment system for farmers to cultivate major food crops such as rice and barley. In some areas, reduction of agricultural tax and the policy change for positive financial support were started. Changes in China's agricultural environment can be inferred to have caused the increase in Japanese research interest in China's agricultural management, such as expansion into the international market and change of domestic policy.

From 2006 to 2010,26 editions (17.1\% of the 152 papers) were published, and the average number of published papers was 5.2 in that year. Although the figures decreased from the peak period, these figures were not at a low level in light of Japanese research trends. The same situation continued even in the next period (2011 to 2016) when 31 papers were published. The average number of published papers recorded was 6.2. From 2006 onwards, maturity stabilization was observed following the peak period.

The research conducted during the maturation period focused particularly on the new agricultural policy developed at the same time and its consequences. One example was the "farm cooperative" that was implemented under the "agricultural specialist collaborative cooperative registration regulation" in 2007 and expanded rapidly nationwide. This policy promoted a cooperative type of organization modeled on the Japanese agricultural cooperative, which jointly conducted sales and purchasing while maintaining small-scale family agricultural management. The "researcher" policy implemented in 2013 also attracted attention and intended to increase land management scale by encouraging farmers to borrow land from other farmers.

\subsection{Classification by Research Theme}

Table 3 summarizes the research issues in the targeted 152 Japanese research papers published from 1980 to 2016 (six periods). These issues can be categorized into 18 problems identified in the aforementioned categories. Overall, 321 issues are present in 
152 papers. Japanese papers on Chinese agricultural management over the past 37 years were written in content composition covering problems at an average number of 2.1. Interestingly, the average number of subjects in the first 10 years was 1.4, which indicates that most of the papers published at this time focused on only one issue. Then, Japanese researchers extended their focus and, in the next decade, most of the papers related to Chinese agricultural management were written in content composition covering two issues. Since 2010, which is the late half of the maturity stability period, the average number of issues mentioned in one paper increased to 2.6. From these results, it became clear that the diversity of Japanese research on Chinese agricultural management gradually increased.

We define the problem categories mentioned in more than $20 \%$ of papers in one period as the "important research topic" during this period. Based on this classification, the framework of Japanese research on Chinese agricultural management can be clarified. The most important research topic is "external conditions," which is the important research topic in all the six periods. "Agricultural management" is the second important research topic because it was mostly mentioned in four of the six periods. "Structure/organization," "livestock," and "cropping organization" were mentioned as important topics in three of the six periods. "Natural condition" is important in two periods. "Agricultural policy," "family management," and "others" were supposed to be important research topics in the first period only. Notably, research on "agricultural management," "structure/organization," and "external condition" were mostly mentioned throughout the past 37 years. These studies treat the agricultural management issues in China as a whole. In other words, Japanese research papers studied the environmental conditions (natural and social) of the agricultural management in China instead of taking a greater interest in the agricultural management itself.

In the past 37 years, research topics from a micro perspective received less attention than those from a macro perspective. Only "family management" is supposed to be important in the late half of the growth period. However, if we loosen the criteria for the importance of research topics from the mentioned frequency of $20 \%-10 \%$, "farmland" and "income" are important research topics in these papers. Furthermore, considering these topics, we can conclude that Japanese research on Chinese agricultural management from a micro perspective focuses on the rural household management with high concern for production factors, such as farmland and income.

"Livestock" is an important research topic during the infancy period. Then, "cropping" became important during the growth period since 1990. The change of research concern about the real agricultural management conditions in China shows the transition in the structure of agricultural production. As expected, problem categories that highly relate to China's contemporaneous government policy, such as "rural areas," "agricultural industrialization," "specialized collaborative cooperation," and "family farms," also received close attention and became important research topics. 
Table 3. Type of Category by Age

\begin{tabular}{|c|c|c|c|c|c|c|c|c|c|c|c|c|}
\hline Year & \multicolumn{2}{|c|}{ 1980-1990 } & \multicolumn{2}{|c|}{ 1991-1995 } & \multicolumn{2}{|c|}{ 1996-2000 } & \multicolumn{2}{|c|}{ 2001-2005 } & \multicolumn{2}{|c|}{ 2006-2010 } & \multicolumn{2}{|c|}{ 2011-2016 } \\
\hline Papers & \multicolumn{2}{|c|}{5} & \multicolumn{2}{|c|}{16} & \multicolumn{2}{|c|}{30} & \multicolumn{2}{|c|}{44} & \multicolumn{2}{|c|}{26} & \multicolumn{2}{|c|}{31} \\
\hline Category & Number & Ratio & $\begin{array}{l}\text { Num } \\
\text { ber }\end{array}$ & Ratio & Number & Ratio & Number & Ratio & Number & Ratio & Number & Ratio \\
\hline $\begin{array}{c}\text { General Agricultural } \\
\text { Management }\end{array}$ & 2 & $\underline{40}$ & 2 & 12.5 & $\underline{6}$ & $\underline{20}$ & 6 & 13.6 & $\underline{7}$ & $\underline{26.9}$ & $\underline{8}$ & $\underline{25.8}$ \\
\hline Agricultural Policy & 1 & $\underline{20}$ & 2 & 12.5 & 1 & 3.3 & 5 & 11.4 & 3 & 11.5 & 3 & 9.7 \\
\hline $\begin{array}{l}\text { Construction/ } \\
\text { Organization }\end{array}$ & 1 & $\underline{20}$ & 3 & 18.8 & $\underline{8}$ & $\underline{26.7}$ & 0 & 0 & 4 & 15.4 & $\underline{9}$ & $\underline{29}$ \\
\hline Natural Conditions & 1 & $\underline{\underline{20}}$ & $\underline{4}$ & $\underline{25}$ & 0 & 0 & 0 & 0 & 2 & 7.7 & 5 & 16.1 \\
\hline External Conditions & 1 & $\underline{20}$ & $\underline{4}$ & $\underline{25}$ & $\underline{10}$ & $\underline{33.3}$ & $\underline{21}$ & $\underline{47.7}$ & $\underline{10}$ & $\underline{38.5}$ & $\underline{14}$ & $\underline{45.2}$ \\
\hline Family Management & 0 & 0 & 3 & 18.8 & $\underline{6}$ & $\underline{20}$ & 5 & 11.4 & 4 & 15.4 & 6 & 19.4 \\
\hline Farmer & 0 & 0 & 1 & 6.3 & 2 & 6.7 & 4 & 9.1 & 2 & 7.7 & 2 & 6.5 \\
\hline Farmland & 0 & 0 & 1 & 6.3 & 3 & 10 & 5 & 11.4 & 0 & 0 & 6 & 19.4 \\
\hline Labor & 0 & 0 & 1 & 6.3 & 1 & 3.3 & 4 & 9.1 & 1 & 3.8 & 3 & 9.7 \\
\hline Income & 0 & 0 & 3 & 18.8 & 0 & 0 & 2 & 4.5 & 3 & 11.5 & 1 & 3.2 \\
\hline Rural & 0 & 0 & 3 & 18.8 & 3 & 10 & 2 & 4.5 & 0 & 0 & 2 & 6.5 \\
\hline $\begin{array}{c}\text { Agricultural } \\
\text { Industrialization }\end{array}$ & 0 & 0 & 0 & 0 & 2 & 6.7 & 1 & 2.3 & 2 & 7.7 & 0 & 0 \\
\hline Farm (family farm) & 0 & 0 & 0 & 0 & 2 & 6.7 & 2 & 4.5 & 1 & 3.8 & 2 & 6.5 \\
\hline Farm Cooperative & 0 & 0 & 0 & 0 & 0 & 0 & 2 & 4.5 & 1 & 3.8 & 2 & 6.5 \\
\hline Livestock & 1 & $\underline{20}$ & $\underline{\mathbf{5}}$ & $\underline{31.3}$ & $\underline{\mathbf{6}}$ & $\underline{20}$ & 3 & 6.8 & 2 & 7.7 & 5 & 16.1 \\
\hline Cropping & 0 & 0 & 1 & 6.3 & $\underline{7}$ & $\underline{23.3}$ & $\underline{15}$ & $\underline{34.1}$ & $\underline{6}$ & $\underline{23.1}$ & 6 & 19.4 \\
\hline International Trade & 0 & 0 & 0 & 0 & 1 & 3.3 & 3 & 6.8 & 1 & 3.8 & 1 & 3.2 \\
\hline Others & 0 & 0 & 0 & 0 & 3 & 10 & 7 & 15.9 & 5 & 19.2 & $\underline{7}$ & $\underline{22.6}$ \\
\hline $\begin{array}{l}\text { ant Research Topics } \\
\text { (over } 20 \% \text { ) }\end{array}$ & \multicolumn{2}{|c|}{6} & \multicolumn{2}{|c|}{3} & \multicolumn{2}{|c|}{6} & \multicolumn{2}{|c|}{2} & \multicolumn{2}{|c|}{3} & \multicolumn{2}{|c|}{4} \\
\hline $\mathrm{r}$ of Subject Areas & \multicolumn{2}{|c|}{6} & \multicolumn{2}{|c|}{15} & \multicolumn{2}{|c|}{15} & \multicolumn{2}{|c|}{16} & \multicolumn{2}{|c|}{16} & \multicolumn{2}{|c|}{17} \\
\hline $\begin{array}{l}\text { Number of Articles } \\
\text { Covered }\end{array}$ & \multicolumn{2}{|c|}{7} & \multicolumn{2}{|c|}{33} & \multicolumn{2}{|c|}{58} & \multicolumn{2}{|c|}{87} & \multicolumn{2}{|c|}{54} & \multicolumn{2}{|c|}{82} \\
\hline :yword Average & 1. & & & .1 & 1. & & 2 & & 2. & & 2. & \\
\hline $\begin{array}{l}\text { arch Development } \\
\text { Stage }\end{array}$ & $\begin{array}{r}\text { Incub } \\
\text { Sta }\end{array}$ & & & $\mathrm{Gr}$ & Stage & & Peak & tage & & 101 & ity Stage & \\
\hline
\end{tabular}

Crops: white rice, vegetables

External conditions: distribution, technology

※Important categories are indicated in bold and underlined format.

\subsection{Classification by Research Theme}

Table 3 summarizes the research issues in the targeted 152 Japanese research papers published from 1980 to 2016 (six periods). These issues can be categorized into 18 problems identified in the aforementioned categories. Overall, 321 issues are present in 152 papers. Japanese papers on Chinese agricultural management over the past 37 years were written in content composition covering problems at an average number of 2.1. Interestingly, the average number of subjects in the first 10 years was 1.4 , which indicates that most of the papers published at this time focused on only one issue. Then, Japanese researchers extended their focus and, in the next decade, most of the papers related to Chinese agricultural management were written in content composition covering two issues. Since 2010, which is the late half of the maturity stability period, the average number of issues mentioned in one paper increased to 2.6. From these 
results, it became clear that the diversity of Japanese research on Chinese agricultural management gradually increased.

We define the problem categories mentioned in more than $20 \%$ of papers in one period as the "important research topic" during this period. Based on this classification, the framework of Japanese research on Chinese agricultural management can be clarified. The most important research topic is "external conditions," which is the important research topic in all the six periods. "Agricultural management" is the second important research topic because it was mostly mentioned in four of the six periods. "Structure/organization," "livestock," and "cropping organization" were mentioned as important topics in three of the six periods. "Natural condition" is important in two periods. "Agricultural policy," "family management," and "others" were supposed to be important research topics in the first period only. Notably, research on "agricultural management," "structure/organization," and "external condition" were mostly mentioned throughout the past 37 years. These studies treat the agricultural management issues in China as a whole. In other words, Japanese research papers studied the environmental conditions (natural and social) of the agricultural management in China instead of taking a greater interest in the agricultural management itself.

In the past 37 years, research topics from a micro perspective received less attention than those from a macro perspective. Only "family management" is supposed to be important in the late half of the growth period. However, if we loosen the criteria for the importance of research topics from the mentioned frequency of $20 \%-10 \%$, "farmland" and "income" are important research topics in these papers. Furthermore, considering these topics, we can conclude that Japanese research on Chinese agricultural management from a micro perspective focuses on the rural household management with high concern for production factors, such as farmland and income.

The relationship between the Japanese research method on Chinese agricultural management and the Chinese government policy can be summarized according to the research situation in the different periods.

(1) Infancy period (1980-1990). Only five publications were found. The six problem categories mentioned were supposed to be important research topics (mentioned by over $20 \%$ of the papers). Each paper discussed 1.4 issues on average. Thus, each paper focused on one specific topic as the main content, namely, "agricultural management," "agricultural policy," "structure/organization," "natural conditions," and "external conditions." These topics received constant attention and became the basic research problem in Japanese analysis framework. Notably, papers written during this period provide the macro-perspective framework of Japanese research on Chinese agricultural management as a whole. In other words, the analytical framework was formed by examining the structure and organization of agricultural management with the macro understanding of its relationship with the environmental conditions (natural and social). Meaningfully, when the Family Production Responsibility System was created and the individual household became the basic unit of China's agricultural transition, the 
Japanese research framework on Chinese agricultural management was established based on the analysis from the macro perspective.

(2) Growth period (1991-2000). A total of 16 publications consisting of 13 topics were written in the early half of this period. Issues mentioned accounted for $72 \%$ of all Japanese research topics on Chinese agricultural management. The interest of Japanese researchers became more diverse, and each paper discussed 2.1 issues on average. Similarly, in the late half of this period, 15 issues were discussed in 30 papers, which accounted for $83 \%$ of all research topics on Chinese agricultural management. Each paper discussed 1.9 issues on average. The diversity of topics and number of research papers on agricultural management in China increased considerably. Therefore, research interest in one specific topic is relatively small. In the early half, "natural condition," "external conditions," and "livestock" were the most important research topics. In the late half, the important research topics increased to six, namely, "agricultural management," "structure/organization," "external condition," "family management," "livestock," and "cropping work." Since this period, studies on rural household management, which consisted of the production factors issues, such as farmland and labor, and the achievement of farmer management issues, such as income, assumed an important position in agricultural management research. These papers formed the microperspective analytical framework. "Agricultural industrialization" was introduced in China during this period to promote the vertical integration of companies and farmers and strengthen agricultural management. As a result, papers on "rural areas" and "agricultural industrialization" were published.

(3) Prosperous period (2001-2005). A total of 44 publications were found, and 16 topics were discussed, which accounted for $89 \%$ of all research topics. The interest of Japanese researchers exhibited faster diversification. Each paper discussed two issues on average during this period. In addition, "external conditions" and "cropping work" received the most concern. A total of $45 \%$ and $34 \%$ of the papers discussed the "external condition" and "cropping work" issues, respectively. This close concern can be connected to China's entry as a WTO member in 2000. Along with the changes in international and domestic agricultural markets, the Chinese government policy corresponding to the structural change of crop cultivation became an important issue for Japanese researchers.

(4) Maturity period (2006-2016). A total of 26 publications were found in the early half, and 16 topics were discussed (covering $89 \%$ of the research topics), indicating that each paper discussed 2.1 issues on average. In the late half, 31 papers were published and 17 topics were discussed, which accounted for $94 \%$ of all research topics. The number of papers and topics shows that the interest of Japanese researchers was increasingly diversifying. At the same time, the diversification tendency of the composition of the papers was further strengthened, and on average, in the early half, one paper was written integrating two issues, whereas in the late half, an average of one paper was written integrating three issues. Furthermore, in the early half, three topics, namely, "agricultural management," "external conditions," and "cultivated works," received the most concern. "Agricultural management," "structure/organization," "external conditions," and "others" were the important research topics in the late half. The primary concern of the Japanese researcher was the subjects linked with a macro 
analytical framework. The structural and systematic understanding of agricultural management based on its relationship with the environmental conditions were still the most important research topics. Although the concern from the micro perspective is relatively low compared with the macro analysis framework, in the latter half, the research topics under the micro-analytical framework for understanding farm management and examining the relation between production factors, such as farmland, labor force, and income, were emphasized. Coincident with the introduction of a strengthened policy for the family agricultural management foundation, cooperation to strengthen small-scale family agricultural management through joint sales and purchasing businesses, as well as home farms to expand management scale through land intensification, were observed.

\subsection{Classification of Articles by Analysis Target Level}

As agriculture production is regionally specified according to natural and external social conditions, clarifying the levels of research framework of China's agricultural management is necessary, considering China's vast territory and the various external environmental conditions. In this section, we will analyze each research subject at each level and clarify the relationship of each level of data being used for that purpose. Table 4 summarizes the analysis and measurement unit level in the targeted papers. Overall, many Japanese studies analyze subjects at the provincial level and are mainly limited to a single province.

Then, we analyzed these research papers using the measurement units. The number of studies using the whole country as a measurement unit was $57(37.5 \%)$, which was the largest overall. A total of 14 studies $(9.2 \%)$ used the provincial unit, $6(3.9 \%)$ used the city, and 11 studies used the prefecture (7.2\%). Only two studies $(1.3 \%)$ used the township, $13(8.6 \%)$ used the village, and $33(21.7 \%)$ used the farmers as measurement units. A total of 16 studies $(10.5 \%)$ used an economic entity that was an intermediate organization located between farmers and consumers as a measurement unit. Studies that dealt with data at the macro-level measurement unit, such as nationwide and provincial levels, are the most numerous at $46.7 \%$, whereas the second most numerous (at 32\%) dealt with data at the micro-level measurement unit, such as farmhouses and other economic agents. This result indicates that the distribution of research papers by measurement unit tends toward bipolar differentiation. However, research that employed data at the intermediate level, such as city and prefecture, was at $11 \%$. Research that dealt with data at the primary level, such as town, and village, is at $10 \%$. The importance of the intermediate-level research approach should be noted.

According to the correlation between the analysis target and measurement unit, 12 papers that analyzed China's trade and 49 papers that analyzed China as a whole were all based on data measured at the national level. The analysis target level and the measurement level are consistent. A total of 10 papers analyzed agricultural management in multiple provinces. Among these papers, only four collected data at the provincial level, one at the township level, two at the village level, and three at the farmer level. Less than half of the papers were characterized by consistent analysis targets and measurement levels. Among 81 papers with a single province as analysis target, only 10 papers collected and measured data at the provincial level. Furthermore, 
a total of 6 papers measured data at the city level, 11 at the prefectural level, 2 at the town level, 13 at the village level, 33 at the farmhouse level, and 16 that studied the economic entity. In other words, when only the single provincial area is analyzed, the measurement at the provincial level itself accounts for $12 \%$ of all research. A total of $21.1 \%$ of the papers measured the middle level, such as the city/prefecture, whereas $15 \%$ referred to the basal level closely related to the area as a measurement unit, such as village or town. A total of $36 \%$ of these measure levels were measured units. Meanwhile, the papers applying measurement at the micro level, including farmer's units, accounted for $32.2 \%$ of the total. Therefore, even when analyzing agricultural management at the provincial level, some microscopic research approaches have been adopted, with farmers and management entities as measurement units

Table 4: Provincial Level and Measurement Unit

\begin{tabular}{|c|c|c|c|c|c|c|c|c|c|c|}
\hline \multirow{3}{*}{$\begin{array}{l}\text { Level } \\
\text { Analysis }\end{array}$} & \multicolumn{8}{|c|}{ Measurement Unit } & & \\
\hline & \multicolumn{2}{|c|}{ Macro } & \multicolumn{4}{|c|}{ Mezzo } & \multicolumn{2}{|c|}{ Micro } & \multirow[b]{2}{*}{ Total } & \multirow[b]{2}{*}{$\begin{array}{l}\text { Rate } \\
(\%)\end{array}$} \\
\hline & China & Province & City & Prefecture & Township & Village & Farmer & $\begin{array}{c}\text { Economic } \\
\text { entity }\end{array}$ & & \\
\hline China overseas & 12 & & & & & & & & 12 & 7.9 \\
\hline China & 45 & & & & & & 1 & 3 & 49 & 32.2 \\
\hline Multiple provinces & & 4 & & & 1 & 2 & 3 & & 10 & 6.6 \\
\hline Single province & & 10 & 6 & 11 & 1 & 11 & 29 & 13 & 81 & 53.3 \\
\hline Papers & 57 & 14 & 6 & 11 & 2 & 13 & 33 & 16 & 152 & 100 \\
\hline $\begin{array}{c}\text { Percentage of papers } \\
(\%)\end{array}$ & 37.5 & 9.2 & 3.9 & 7.2 & 1.3 & 8.6 & 21.7 & 10.5 & 100 & \\
\hline Level (\%) & & 6.7 & & & 1.1 & & & 2.2 & 100 & \\
\hline
\end{tabular}

Note: "China overseas" refers to China and Japan, East Asia, and Korea.

"Multiple provinces" are Sichuan, Anhui, Heilongjiang, Inner Mongolia, Shanxi, and Shandong.

"Administrative agencies in China" are country, province, city, prefecture, township, and village.

In recent years, government policies have strengthened the polarization of agriculture management in China. Examples are the "family farm" policy to promote large-scale, family-managed farming and the "specialized collaborators" policy to integrate small individual agricultural units with the leading (longtou) enterprise. Table 5 shows the new emerging agricultural management type in China. The "family farm" policy targets 17 million farmers who own more than $50 \mathrm{mu}(3.33 \mathrm{ha})$ of farmland, which is equivalent to approximately seven times of the household average land area, and 0.87 million farmers who own more than $200 \mathrm{mu}$ (13.33 ha) of farmland. This policy aims to concentrate $60 \%$ of all agricultural land in China, which is owned by these farmers for agricultural management. The "specialized collaborators" policy targets the small household farmers who own less than eight mu of farmland. By strengthening the cooperation between "leading (longtou) enterprises" and individual farmers in a vertical integration, agricultural industrialization can be promoted, such as joint sales and mechanization of agricultural production. The accumulation of $20 \%$ of the total farmland was planned by cultivating 120,000 leading enterprises; $10 \%$ of all farmlands; and 1,270 specialized cooperatives. Consequently, rather than focusing on small-scale family agricultural management itself, focusing on the agricultural management in regions and on the relationships among farmers becomes an critical issue in recent Japanese research. 
Published by Hasanuddin University and Asian Rural Sociology Association

Table 5: New Management Types

\begin{tabular}{c|c|c|c}
\hline & $\begin{array}{c}\text { Scale } \\
(\mathrm{mu})\end{array}$ & $\begin{array}{c}\text { Number } \\
\text { (thousand) }\end{array}$ & $\begin{array}{c}\text { Agricultural integration } \\
\text { composition (\%) }\end{array}$ \\
\hline Family farm (door) & Over 200 & 877 & $60.30 \%$ \\
\cline { 2 - 3 } & Over 50 & 3,170 & $20.40 \%$ \\
\hline Farm cooperative (union) & 1,267 & $9.40 \%$ \\
\hline $\begin{array}{c}\text { Agricultural industrialization } \\
\text { (company) }\end{array}$ & 120 & \\
\hline
\end{tabular}

Source: "Agricultural Reform in China and Development of Large-scale Agricultural Management: Focusing on

Reform of Land System and Production Organization” (China Agriculture Great Change), 54 (2016)

\section{Conclusions}

In the present study, we analyzed 152 Japanese research papers related to agricultural management in China from three perspectives: as a period group, subject category, and measurement scale. We defined six periods in the past 37 years, and under this period classification, we extracted issues that were directly related to the research theme. Furthermore, we aimed to figure out the characteristics of the analysis under various measurement scales.

Considering the number of papers, the percentage of these papers during the entire period, and the number of yearly average publications, we defined the following four stages of Japanese research on the Chinese agricultural management: infancy, growth, prosperous, and maturity periods. Using the keywords from the titles of the 152 papers, we classified 18 categories of problems that have been discussed in these papers and grouped them under different periods. From this organization, we analyzed the overall research framework of Japanese papers and the topics that the researcher focused on in the different periods. From the former results, the universality found in Chinese family agricultural management research can be reflected. The latter results reflect the change in Chinese agriculture in each period and the corresponding policy development of the government. We summarize the important results as follows:

Changes in agricultural production structure reflect the changes in food demand, which accompanied China's economic growth. "Cropping work" became an important topic in the late half of the growth period of the Japanese research work. "Cropping work" refers not only to the production process itself but also to the relationship between production and market, such as production technology, distribution, and access to the market. Japanese researchers investigated the policy that focused on promoting the leading enterprise, aiming for vertical integration of management, and the policy that focused on promoting the cooperative in the "specialized cooperation company" aiming at horizontal integration of management. However, case studies that can confirm these results and reflect the manner of research have to be generated in the future.

Future studies should emphasize the agricultural management of the small household farmer, as well as the framework of the entire farming economy with focus on the agricultural land (i.e., the means of production) and the distribution and use of labor. Understanding the relationship between the agricultural and non-agricultural work of the farmer is necessary. 
In addition, research on the family management in China has been divided into two directions. One direction is to clarify the characteristics of small family management and study solutions for problems on the premise of these characteristics. Studies on the vertical and horizontal integrations of management description are related to this direction. Some researchers have started to work on the issues of land scale expansion, which prescribes the characteristics of small family management. These two different research directions have reflected the diversification of the agricultural management policies implemented by the Chinese government in recent years. However, in contrast to the research on small family management, that on the expansion of land scale for family management in China needs accumulation.

Despite the importance of the studies at the local level, such as measuring the village and county units, most of the Chinese statistical database for the rural sector have been published only at the city-unit level. Data at the prefecture level have not been published. Therefore, the necessity and significance of empirical research at the mezzo and micro levels of the prefecture, township, village, farmers, and economic entity should be emphasized.

\section{Note}

(1) The results of searching for " Chinese agricultural management"(Japanese : 中国農業経営) were 630, since it contains the Chugoku District in Japan. Eventually, there are 152 papers which takes China as study object.

\section{References}

Goro, T. (2008). "The Conversion of the Chinese Economy and Agriculture - Future of Food and Environment" pp. $111-145$

Kawakita, J. (1996). Let's Talk After the KJ Method Chaotic, Central Public Opinion Company

Kazuyoshi, S. (1997) "China Agriculture Must Necessarily" Agriculture mountain fishing village culture association pp.76

Lee Young-baek. (2011). Land Public Ownership System in China Rural Village and Its Legal Analysis, Yo Shobo Ltd.

Oshima, K. (2016) Agricultural Reform in China and Development of Large Scale Farm Management: Focusing on Reform of Land System and Production Organization (Feature: China Agriculture Great Change) China 21: 44, pp.47-62

Suganuma, K. (2016). "Food situation in China - Transfiguration of Chinese Rural Society and the Way of Family Farming Management" Agriculture No.1613 pp.627 